Voix et Images

voixetimages

\title{
L’écriture moderne. Encore. Enfin
}

\section{Jean Fisette}

Volume 4, numéro 1, septembre 1978

Rina Lasnier

URI : https://id.erudit.org/iderudit/200145ar

DOI : https://doi.org/10.7202/200145ar

Aller au sommaire du numéro

Éditeur(s)

Les Presses de l'Université du Québec

ISSN

0318-9201 (imprimé)

1705-933X (numérique)

Découvrir la revue

Citer cet article

Fisette, J. (1978). L'écriture moderne. Encore. Enfin. Voix et Images, 4(1),

148-150. https://doi.org/10.7202/200145ar

Ce document est protégé par la loi sur le droit d'auteur. L'utilisation des services d'Érudit (y compris la reproduction) est assujettie à sa politique d'utilisation que vous pouvez consulter en ligne.

https://apropos.erudit.org/fr/usagers/politique-dutilisation/
Cet article est diffusé et préservé par Érudit.

Érudit est un consortium interuniversitaire sans but lucratif composé de l’Université de Montréal, l'Université Laval et l'Université du Québec à Montréal. Il a pour mission la promotion et la valorisation de la recherche. https://www.erudit.org/fr/ 


\section{L'écriture moderne. Encore. Enfin}

Ce volume comprend les rééditions de deux recueils déjà parus aux Herbes rouges, soit: Nattes (Herbes rouges $n^{\circ} 18,1974$ ) et Les dents voient (Herbes rouges $n^{\circ} 39-40,1976$ ). Tout va bien (Aurore, 1975). Ainsi que deux textes inédits : les Grandes Lères, quelques textes datés de 19711972 et surtout: Car tendresse, un volumineux recueil de textes datés de 1976-1977.

Les autres textes étant déjà connus, je m'arrête, par goût, par intérêt, par plaisir à Car tendresse (p. 209-303)

Enfin l'écriture moderne commence de produire de grands textes. Les promesses des théoriciens n'auront pas été, quoiqu'on ait pu en dire, de vains mirages. Nonobstant l'enthousiasme du moment - qui m'emporte peut-être - Car tendresse marque une importante étape de maturation dans l'aventure de l'écriture moderne au Québec. (Et l'on saura gré à VLB Éditeur de publier un tel livre à un coût si bas!)

Le premier aspect qui me frappe, c'est l'originalité du rapport forme-contenu et Haeck, si je ne m'abuse, est un innovateur en ce qu'il réussit à faire sortir la poésie de l'ornière lyrico-symboliste où elle s'engluait depuis le tournant du siècle et d'où le surréalisme n'avait pas réussi à la dégager. En termes plus techniques : la poésie est devenue textualité, écriture, appel des mots par les mots : tous les "sujets " sont conviés...

Non plus simplement épanchement sentimental ou exploitation de l'onirisme baroque : toutes les questions de l'heure - mêmes les plus théoriques et les plus abstraites - sont présentes : le désir, l'écriture, la dialectique, le projet de société, les préoccupations épistémologiques, etc.

Ici, à l'évidence, la «poéticité», loin de correspondre à un “esthétisme " tout corseté, est le fait d'une pensée à voix haute ou, plutôt, écrite comme dans un murmure : j'emploierais le qualificatif de "feutré" pour caractériser cette production d'écriture : les cheminements de l'imaginaire sont étalés, constitutifs du texte même.

Un adolescent vient déjeuner en couvrant son pénis de ses mains il pleut. La pluie est bonne. Elle a une façon de mouiller les concepts qui les rend tout gondolés: ils valent alors autant qu'une paire de jeans.

Une intelligence mouillée: pour le plaisir. (P. 215.)

Voilà: mouvement d'une imagination qui va, sans ordre autre que celui de la séquence, d'une image de repli sur soi à la tristesse de la pluie, à un étalement de cet indice, à une acceptation: la tristesse conduit au bonheur de s'assumer: pour le plaisir! La fluidité. 
Du texte non sentimental certes (dans ces conditions d'écriture, ce serait irrespirable) mais empreint d'une tendresse comme le proclame le titre. La section intitulée: "Près d'elle" traduit une sensibilité toute contemporaine, la vie du jeune couple.

La vie de couple quand elle permet de sentir la solitude de l'un et de l'autre produit des tensions qui activent le cœuraison infiniment plus que ne saurait le faire la vie solitaire. II y a dans la netteté des différences, des séparations, une envie folle de jouissances. De là une réserve innombrable pour des solidarités neuves, savante de toutes les tensions qu'il y a dans un vivre ensemble, des solidarités de béliers qui savent la courbe de leurs cornes. (P. 263.)

L'image finale, on le sent immédiatement à la lecture, loin de servir d'alibi à une construction formelle, est le point d'aboutissement du parcours textuel. Aussi point de départ de l'imaginaire. II n'y a plus ici de décoration, de carton-pâte mais un enchaînement, des ouvertures... Non plus des objets poétiques disposés à la queue-leu-leu comme sur une étagère de musée, mais un mouvement unique, une dynamique, un devenir...

Si l'on trouve parsemées ici et là des marques d'engagement sociopolitique, ce n'est plus le ton de proclamation et d'interdiction confinant à la tautologie qui caractérisait l'Action restreinte / De la littérature (L'Aurore, 1974) qui avait d'ailleurs valu à l'auteur le comique surnom de "gendarme de la littérature». Comparez:

Travailler à l'avancée de la littérature réaliste, c'est participer à la grande affaire réaliste. [sic] (L'Action restreinte, p. 63).

La parole d'écriture, parole de contestation incessante se développe et se rompt sous des formes multiples. La parole communiste toujours à la fois tacite et violente, politique et savante, indirecte, totale et fragmentaire, longue et presque instantanée.

Je propose de la décrire en ayant recours à une espèce de météorologie qui indiquerait les déplacements des masses d'air, les pressions, les courants, les températures, les nuages, les précipitations,... (Car tendresse, p. 23.)

Appellera-t-on ces textes poésies? Ou bien : apophtegmes, pensées, etc... Peu importe si ce n'est que Haeck a trouvé une heureuse solution au problème central des Herbes rouges, celui de la lisibilité. Lui pardonnera-t-on? Haeck serait alors à situer dans la même lignée que De Bellefeuille, celle de l'écriture dont l'éclatement à été assumé. Dépassement de la forme fixe du poème dont le trope, trop ponctuel fige le texte, interdit la fluidité, l'écoulement, la transparence...

Les maîtres d'hier, précédemment adorés ou honnis, ont tous laissé leur heureuse trace et je nomme, entre autres, Paul-Marie Lapointe (du Vierge incendié, le «poète absolu»), Rolland Giguère. Les poètes dépassés, par-là même honorés. Le temps est au plaisir, enfin! 
L'on a, depuis quelques temps, proclamé la mort de l'Hexagone (ce qui n'est peut-être pas faux). Certains prophètes, maintenant à l'ombre du pouvoir, s'abritant sous l'alibi du folklore nationalisé, ont conclu au tarissement de la source littéraire au Québec. Ce qui, paradoxalement, manifeste une bien piètre confiance en l'avenir.

Pourtant la génération nouvelle est là, à pied d'œuvre: Brossard, LaRocque, Haeck... Dos écrivains purs!

Jean Fisette,

Université du Québec à. Montréal 